\title{
RESENHA DE EPÍGRAFES E DIÁLOGOS NA POESIA DE MACHADO DE ASSIS, DE AUDREY LUDMILLA DO NASCIMENTO MIASSO
}

\section{REVIEW OF EPÍGRAFES E DIÁLOGOS NA POESIA DE MACHADO DE ASSIS, BY AUDREY LUDMILLA DO NASCIMENTO MIASSO}

MIASSO, Audrey Ludmilla do Nascimento. Epígrafes e diálogos na poesia de Machado de Assis. São Carlos: EdUFSCar. 2017. 505 p.

\section{MARIA CRISTINA CARDOSO RIBAS}

Universidade do Estado do Rio de Janeiro

Rio de Janeiro, Rio de Janeiro, Brasil

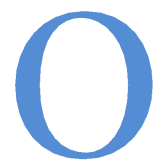

título deste livro, circunscrito a epígrafes machadianas, pode suscitar uma curiosidade mais imediata: como epígrafes, tidas pelo senso comum (do qual, em alguns momentos, somos todos partícipes) como adorno ou ateste de erudição, justificam a existência de um trabalho dessas proporções?

A questão provavelmente advém de uma tendência contemporânea: o automatismo de determinados olhares compromete a percepção das sutilezas discursivas, o que torna quase invisível - a este modo de ver - a presença de textualidades interligadas e justapostas, tidas como acessório do elemento principal. Neste distúrbio de refração ocular, utilizando lentes adequadas para refocalizar o objeto e neutralizar a miopia discursiva, tenazmente instalada no delicado espaço entre a citação e o poema, lado à "paixão pelo gesto arcaico de recortar-colar" (COMPAGNON, 1996, p. 12), Audrey Ludmilla do Nascimento Miasso percebeu a distorção do foco, traduzida em aparente desinteresse, a qual redundou na escassez de estudos sobre o tema.

A pesquisadora estuda o projeto poético machadiano desde 2008 , tendo publicado vários trabalhos sobre o tema (MIASSO, 2016). Sua dissertação de 
Machado de Assis em Linha — Universidade de São Paulo

http://machadodeassis.fflch.usp.br

mestrado - defendida junto ao Programa de Pós-graduação em Estudos de Literatura (PPGLit) da UFSCar e orientada por Wilton Marques, professor do Departamento de Letras dessa Universidade -, foi transformada, com apoio da Fapesp, no livro que ora temos em mãos.

$\mathrm{Na}$ apresentação do volume, Hélio de Seixas Guimarães refere-se à leitura em espiral das epígrafes machadianas, imagem bastante adequada ao livro de Audrey, justamente por sinalizar a importância da dinâmica de um retorno que, passando pelos mesmos lugares, vai também além deles, formulando novas possibilidades significativas. Para o crítico e pesquisador da USP, a autora busca "examinar um problema aparentemente periférico e menor em seus mais variados aspectos, ampliando seu alcance e tirando dele consequências que extrapolam em muito a delimitação de seu ponto de partida" (GUIMARÃES, 2017, p. 11). E mais: diante da constatação de que as epígrafes vão diminuindo ao longo da obra poética, Hélio Guimarães retoma a imagem da autora em sua hipótese: como se elas escorressem pelos versos e estrofes, misturando-se a elas.

Vale dizer que o livro de Audrey sobre as epígrafes machadianas traz também uma epígrafe quase autoexplicativa, de Jean Michel Massa (1971) forte presença no livro organizado por Jobim (MASSA, 2001) sobre a biblioteca de Machado de Assis. Pinçada com precisão pela autora, a citação de Massa ilustra a estratégia de citação machadiana, o seu modo de "recortacola" tão milimetricamente descrito no livro. Escrita encadeada, a autora trabalha as epígrafes de Machado formulando uma composição epigráfica, desenhando as citações dentro das citações, trazendo à cena a montagem da montagem de Machado, hábil operador que copia, refaz, suprime, traduz, deforma, esquece, modifica, ilumina, erra.

Passando a apresentação espiralada de Hélio Guimarães e a epígrafe de Massa, adentramos o primeiro capítulo. Em tom de convite, a autora nos convoca: "De início, vamos ao encontro de Machado adolescente, contando com seus quinze anos e já poeta" (MIASSO, 2017, p. 37). E segue historiando as primeiras publicações, inclusive aquelas anteriores à fama do bruxo do Cosme Velho e ao seu (re)conhecimento pelo público. Gentilmente, a autora vai pincelando informações consensuais, como o dado de que o periódico de Paula Brito fora o principal meio em que ele publicaria seus versos até 1858. Lançando mão do "nós" - "vamos"... "notamos"... salta aos "nossos" olhos... na autorreferência da própria voz, vai obtendo um efeito inclusivo e afeito ao leitor, dispersando informações em doses homeopáticas. Curiosamente, a dispersão dos dados atravessa a organização sequencial dos poemas, 
Machado de Assis em Linha — Universidade de São Paulo

http://machadodeassis.fflch.usp.br

mobilizando intertextos que se justapõem, segundo a acurada pesquisa da autora, no modo composicional das epígrafes machadianas.

Dentre os inúmeros exemplos que se desdobram ao longo dos capítulos, vão sendo compartilhados os efeitos dessas epígrafes sobre a leitura, inclusive quando rareiam ou deixam de aparecer. Pelas minuciosas descrições apresentadas, não soam como aleatórias. Ao falar de Crisálidas, Audrey ressalta a epígrafe traduzida para o português e extraída das Méditations poétiques (1820), de Alphonse de Lamartine, ainda que, conforme a autora, no Inventário proposto por Jean-Michel Massa não seja citada a obra de Lamartine. A primeira conclusão resultante neste trecho é o efeito da tomada de um poeta romântico francês. Nas palavras da autora, "[...] alerta o leitor de qual será a visão que o jovem crítico apresentará da poesia". Citando aqui a epígrafe, antecedida pela questão "o que é a poesia?", lê-se: "uma palavra que o anjo das harmonias segreda no mais íntimo d'alma" (MIASSO, 2017, p. 39).

Nas linhas seguintes (MIASSO, 2017, p. 41), ela faz reverberar, no leitor, o seu propósito: "Tentar encontrar aquilo que saltava aos olhos de Machado no início de sua carreira". Ao mesmo tempo, vai instalando a dúvida na estratégia machadiana de captação das epígrafes: a proveniência é direto da fonte, ou colhida à epígrafe de outrem, citação da citação, fragmento em segundo ou terceiro grau - como, por exemplo, relata acerca dos versos de Dumas pai no poema "Vem!" (publicado em O Paraíba, 11/4/1858): "se teriam sido retirados de sua fonte primeira, a peça 'Teresa' (1832), ou teriam sido reaproveitados da epígrafe de Álvares de Azevedo" (MIASSO, 2017, p. 44). Seguem informações minuciosas acerca deste procedimento - que a autora chama, sem lastro pejorativo, na expressão de Genette (2009), de "aproveitamento de segunda mão" -, bem como de suas repercussões no sentido e no teor composicional dos versos. Deste exemplo bastante detalhado, algumas conclusões merecem realce. Nas palavras da autora: 1 . Decorre o possível equívoco de pensar "que a epígrafe funciona da mesma maneira nos diferentes poemas que dela se apropriam"; 2. Urge, portanto, o entendimento de que "A epígrafe não é um corpo extático e não tem seu sentido definido", mas [a autora cita Compagnon (1996, p. 48)], "muda de sentido segundo a força que se apropria dela: ela tem tantos sentidos quantas são as forças suscetíveis de se apoderar dela" (MIASSO, 2017, p. 45). Com isso, Audrey ativa o diálogo intertextual e intersubjetivo da grafia poética, ressaltando a potência não de sua precisão, mas de sua instabilidade e incompletude. 
Ao mencionar outro poema dentre os dispersos que escolhe destacar "Teu canto" (publicado em A Marmota Fluminense, 15/7/1855) -, a pesquisadora ressalta o fato de a epígrafe ser assinada "pelo próprio Machado". Em sua análise, conclui que a predileção machadiana em fase inicial de carreira poderia ser pela própria epígrafe, em lugar de considerá-la apenas um meio para reafirmar suas leituras; ou seja, reitera o procedimento como tática para dar pistas ao leitor sobre o que viria ler e produzir. E arremata seu entendimento, aproximando-o do que Genette (2009) chamou de efeito-epígrafe.

A seguir, e em vários outros momentos, a autora sinaliza o quanto as epígrafes sugerem a conexão dos primeiros poemas machadianos com o romantismo francês, relatando que, até 1864, algumas delas são colhidas a Victor Hugo, Alexandre Dumas, Alfred Musset, Gautier e La Rochefoucauld; com o romantismo português de Almeida Garrett e o romantismo brasileiro de Magalhães, Gonçalves Dias e Álvares de Azevedo. Importante lembrar as fortes conexões anteriores ao Romantismo como a ligação visceral com Shakespeare, com a Bíblia - Machado era fã do Eclesiastes - e, em menor escala, com textos históricos dos livros da Crônica da Companhia de Jesus e da História dos índios cavaleiros.

A autora traz, ainda, o apoio do discurso cronístico machadiano, sobretudo a parte publicada em A Semana, O Cruzeiro e A Marmota. Interessante observar que Machado imita e ressignifica passagens e imagens bíblicas presentes no imaginário ocidental, através da aparente repetição da fonte. A diferença se instala justamente na repetição do evento ou forma imagética, ancorada na suposta fidelidade que a crescente respeitabilidade conferida a Machado garantia junto ao público leitor.

A autora investe tenazmente nas pistas que desentranha às epígrafes machadianas e as rastreia com precisão de escavadora. Movimento propulsor da pesquisa, no início ela aposta na veracidade dos indícios. Sabiamente abre, porém, espaço para a ambiguidade. Onde há fumaça pode haver não apenas fogo, mas lentes embaçadas que impedem a percepção de que indícios podem representar despistes ou funcionar como deflagradores de um turning point na leitura. Machado trabalhou as epígrafes e as respectivas referências com omissão, erro ou detalhamento nem sempre explícitos dos lugares de captação.

Nas palavras da autora, sobre a leitura dos poemas epigrafados incide um "momento de interpretação", não bastando a percepção da intertextualidade ou o reconhecimento da fonte. Com esta perspectiva, as 
Machado de Assis em Linha — Universidade de São Paulo

http://machadodeassis.fflch.usp.br

epígrafes se desdobram e deixam ver o lado informativo sobre os contextos de produção, os dados objetivos circunscritos à publicação pelas editoras, os contratos materiais e pactos de leitura implícitos assinados por Machado, os projetos dos poemas, e a problematização de hipóteses e efeitos de sentido que interseccionam tais esferas no momento da leitura. Por um viés visto até então como menor, o trabalho de Audrey é primoroso e acessa, pelo detalhe, no desfiar da bainha, a complexidade da escrita de Machado em suas eternas e humanas contradi(c)ções. "As capas de algodão têm agora franjas de seda, como as de veludo tiveram franjas de algodão [...]" (ASSIS, 1884, p. 15). Este livro abre, pelas bordas, um espaço interessantíssimo para os leitores e estudiosos de Machado. Vale a convocação.

\section{Referências}

ASSIS, Machado de. A igreja do diabo. In: . Histórias sem data. Rio de Janeiro: Garnier, 1884.

COMPAGNON, Antoine. O trabalho da citação. Belo Horizonte: UFMG, 1996.

GENETTE, Gérard. Epígrafes. In: Paratextos editoriais. São Paulo: Ateliê Editorial, 2009.

GUIMARÃES, Hélio de Seixas. Apresentação. In: MIASSO, Audrey Ludmilla do Nascimento. Epígrafes e diálogos na poesia de Machado de Assis. São Carlos: EdUFSCar, 2017.

MASSA, Jean Michel. A biblioteca de Machado de Assis: quarenta anos depois. In: JOBIM, José Luís. A biblioteca de Machado de Assis. Rio de Janeiro: ABL; Topbooks, 2001. p. 21-91.

A juventude de Machado de Assis. Rio de Janeiro: Civilização Brasileira, 1971.

MIASSO, Audrey Ludmilla do Nascimento. Epígrafes e diálogos na poesia de Machado de Assis. São Carlos: EdUFSCar, 2017.

. O diálogo bíblico em "A cristã nova", de Machado de Assis. In: ALMEIDA, Kenia Maria de; PEREIRA, João Paulo; SILVA, Ayub Glenda (Orgs.). A poesia e a bíblia: entre a reverência e a paródia. Uberlândia: Edibrás, 2016.

MARIA CRISTINA CARDOSO RIBAS é Professora Associada da Universidade do Estado do Rio de Janeiro, Procientista Uerj/Faperj e membro efetivo do Programa de Pósgraduação em Letras no Instituto de Letras, Uerj e do Programa de Pós-graduação em Letras e Linguística da Faculdade de Formação de Professores da Uerj. A área de concentração é Literatura, Teoria e História e as linhas de pesquisa são Teoria Literária, Literatura Comparada, Literatura Brasileira e Estudos de Intermidialidade. Concluiu o Pós- 
Machado de Assis em Linha — Universidade de São Paulo

http://machadodeassis.fflch.usp.br

doutorado na Universidade Federal Fluminense. Publicou, entre outros trabalhos, Onze anos de correspondência: os machados de Assis, pela 7Letras e PUC-Rio; "Re-reading Literature in Contemporary Cinema: Intermediality in Machado de Assis' Story "Father Against Mother" (1906) and Sergio Bianchi's film How much is it worth or is it per kilo?" (In: Brigitte Le Juez; Nina Shiel; Mark Wallace (Orgs.). (Re)writing without borders: contemporary intermedial perspectives on literature and the visual arts, 2005); "0 tempo na narrativa machadiana ou quando a ficção refaz a ciência" (Rivista di Studi Portoghesi e Brasiliani); Estudo a O Alienista: a ciência da loucura e a loucura da ciência, pela EdUerj. Email: marycrisribas@gmail.com

Recebido: 25.01.2019

Aprovado: 01.03.2019 